\title{
Direito e valores no pensamento de Miguel Reale
}

\author{
Luigi Bagolini \\ Catedrático de Filosofia do Direito \\ na 'Universidade' de Gênova
}

1. Duas tendências fundamentais parecem caracteterizar, hoje mais do que nunca, a realidade jurídica, duas tendências que correspondem a exigências imprescindíveis : de um lado, a certeza e a objetividade da regra jurídica, de outro, a necessidade de que ela se adapte à realidade cada vez mais mutável das situações históricas e ideológicas nas quais tem vigência.

Certeza objetiva e adequação às transformações da realidade social são duas necessidades das quais o ordenamento jurídico não pode prescindir, mas são também duas tendências suscetíveis de aparecer entre si contrastantes e irredutiveis. Êste dualismo entre a exigência de certeza e de objetividade das normas jurídicas e a necessidade prática de sua adaptação assim que se alteram as situações sociais, é particularmente sentido nos períodos de crise, de transformação dos valores ideológicos e de conflito entre os interêsses dominantes em uma determinada si-tuação histórica. Torna-se mais sentido ainda nos países que se acham em um processo de evolução econômica muito intenso, onde se nota a presença de elementos culturais diversos e heterogêneos. É o que acontece atualmente no Brasil.

$O$ interêsse que o ambiente brasileiro oferece ao observador dos fenômenos econômicos, sociais e jurídicos é 
alimentado pela extrema variedade dinâmica de seus elementos constitutivos sob os mais variados aspectos, no âmbito de um fundo cultural comum lusitano. A mentalidade jurídica brasileira, quando consegue verdadeiramente exprimir a autenticidade dos fenômenos aos quais se volve, não pode ser uma mentalidade puramente tecnicista, nem puramente formalista ou normativista.

Os grandes juristas brasileiros, como Teixeira de Freitas, Lafayette, Pimenta Bueno, Clovis Bevilaqua e Rui Barbosa (1), mesmo quando usam os métodos europeus, revelam sempre uma receptividade e uma exigência sociológica que lhes é imposta pela dinâmica do ambiente.

Miguel Reale (2), cujos ensaios representam hoje, a meu ver, a mais importante e penetrante expressão da filosofia jurídica brasileira, vê nas posições opostas do puro

(1) A êstes se podem acrescentar outros nomes de notável relêvo como o de João Arruda espírito verdadeiramente sutil, como se depreende dos ensáios pôstumos de recente publicação: Sessenta anos de vida forense, S. Paulo, 1950.

(2) O pensamento jusfilosófico de Miguel Reale, professor de Filosofia do Direito na Faculdade de Direito da Universidade de S. Paulo, é uma das expressões mais carecterísticas e fundamentais da cultura sulamericana contemporânea. São conhecidos os seus dois volumes publicados em 1940: Fundamentos do Direito è Teoría do Direito e do Estado.. Sucessivamente tem produzido ensaios históricos de particular interêsse, entre os quais Liberdade antiga e liberdade moderna (in "Revista da Universidade de S. Paulo", 1950); G. B. Vico, a jurisprudência e. a descoberta do mundo da cultura (in "Revista de Filosofia" 1951). Como histórico especialista da cultura brasileira publicou dois preciosos trabalhos: Posição de Rui Barbosa no mundo da filosofia (S. Paulo, 1949) e A doutrina de Kant no Brasil (SS.) Paulo, .949). Fundador e diretor da Revista Brasileira de Filosofia, Miguel Reale reúne e exprime as mais rvlivas exigências culturais de seu pais. Os seus escritos, a que me refiro especialmente no texto, são: As três acepcõs fundamentais da palavra Direito (in "Revista da Faculdade de Direito", S. Paulo, 1949), De dignitate jurisprudentiae (S. Paulo, 1951) e Axiologia e teleologia 
normativismo e do sociologismo jurídicos as expressões teóricas de uma crise do direito que se enquadra na crise da cultura contemporânea (3).

A crise da cultura contemporânea está ligada a um rápido processo de transformação dos valores, dos fins e dos interêsses fundamentais dos diversos ambientes sociais. Acontece por isso que uma lei passa a vaier em um meio social com características diversas relativamente ao tempo em que foi promulgada. A lei mantem-se formal e literalmente a mesma, mas o seu significado pode mudar no que diz respeito às mutações da convivência em que se aplica.

O puro formalismo ou o puro tecnicismo jurídico e todos os seus teoremas e corolários são por isso insuficientes. Assim, por exemplo, as teorias formais que excluem a priori as lacunas do direito positivo; que consideram como pseudoproblema o problema dos destinatários das normas jurídicas; que circunscrevem o fenômeno do direito positivo entre os limites abstratos assinalados pelo dogma da estatualidade do direito; que concebem a interpretação jurídica como puramente declarativa e silogística, excluindo a priori o significado jurídico de uma interpretação evolutiva e teleológica; que consideram sem significado jurídico-positivo o conceito de abuso do direito e o julgam contraditório em si mesmo, todos êstes e outros modos particulares de considerar os vários aspectos do fenômeno jurídico são unilaterais e parciais.

(introdução à edição em língua portuguêsa de um trabalho que escrevi sôbre Adam Smith.)

Uso nas citações as respectivas abreviações: Acepç̃es, De dignitate, Axiologia. Entre os críticos que mais exatamente têm interpretado o pensamento de Reale vêde J. L. Kunz no ensaio: Zur Problematik der Rechtsphilophie UM die MitTe DES ZWANZIGSTEN JAHRHUNDETS in "OSTERR, ZEITSCHRIFT FÜr ÖFFENTLiGhes Recht", B. IV, 1951, p. 13.

(3) DE Dignitate, \$. 23. 
Partem, no fundo, do pressuposto abstrato de que a regra jurídica seja em si cognoscível como realidade completa e perfeita em si mesma, antes e independentemente de sua aplicação aos casos concretos. Semelhante pressuposto encontra evidentemente correspondência na exigência de salvaguardar-se a certeza e a objetividade da norma jurídica.

No entanto, esta exigência, desenvolvida ao máximo e conduzida ao limite de sua extrema coerência técnica, analítica e formal, tal como se revela nas referidas teorias, conduz a um dramático paradoxo. E' que a exigência da certeza do direito levada a seu limite extremo é suscetível de converter-se na impossibilidade, para o direito positivo, de servir às necessidades concretas e atuais da sociedade, na impossibilidade de adaptar-se aos interêsses presentes da sociedade e, por conseguinte, na impossibilidade de desempenhar, afinal, uma função de justiça.

As mais válidas críticas que têm sido feitas nos ultimos tempos contra o formalismo jurídico, contra o puro normativismo e o puro tecnicismo; as várias teorias da instituição, do ordenamento, da solidariedade, da pluralidade da ordem jurídica positiva; a defesa do caráter teleológico da interpretação; a salvaguarda daquelas que poderiamos chamar janelas abertas do ordenamento jurídico, em contraste com a concepção fechada do mesmo ordenamento concebido como desprovido de lacunas; a elaboração dé uma teoria do abuso do direito, todas estas atitudes teóricas são no fundo dominadas pelo fundado desejo de preservar a função concreta do direito no tocante a seu conteúdo histórico e social.

De um lado, há precisão de certeza; de outro, necessidade de "esprit de souplesse": a necessidade de considerar o direito em função de sua adaptabilidade à realidade social, e a convicção de que a verdade da regra juridica não se descobre antes de sua aplicação, mas se 
constitui e se revela sòmente atravès dela, de modo que "per factum cognoscitur ius".

Miguel Reale em suas páginas vibrantes e coloridas, nas quais o espírito prático do advogado e a sensibilidade do político se manifestam em termos de uma rigorosa coerência filosófica, demonstra com grande clareza em que consistem os limites e as contradiçóes das teorias que são unilateralmente dominadas por uma ou outra das duas mencionadas exigências (4).

2. O fenômeno jurídico é uma unidade de forma e de conteúdo. Forma e conteúdo são dois elementos q̨ue interferem um no outro, sem jamais se resolverem ou se anularem um no outro. A exigência de salvaguardar a certeza e a objetividade da norma jurídica, levada a seu máximo limite, pode fazer com que se perca o conteúdo do direito; e, recìprocamente, a preocupação de fazer valer e de salvar o conteúdo do direito em tôda a particularidade de suas determinações sociais pode conduzir ao direito livre, ̀̀ perda de qualquer objetividade assim como da certeza verdadeira e própria da norma juridica.

Ora, ante estas duas possibilidades extremas, Reale põe em justo relêvo o caráter da ciência do direito e da jurisprudência como forma de conhecimento no qual as duas citadas exigências devem corrigir-se e implicar-se mùtuamente sem se dissolverem uma na outra (5). Entretanto, o ponto de vista do autor não se reduz à perspectiva de uma intercomunicação eclética.

O fenômeno jurídico concreto, em todos os seus aspectos, é sempre caracterizado por um fato social que assume a forma objetiva da certeza legal. E que vem a

(4) Ib., pp. 21-27. Cfr. Teoria do Direito e do Estado, cit., a pp. 25-26 o importante parágrafo: Elogio do meio termo.

(5) Cfr. Fundamentos do Diaeito, cit., pp. 274-320. 
ser fato social? ṫ um conjunto de interêsses humanos. Os interêsses em seu conjunto assumem a forma objetiva da certeza legal quando, mediante um sistema de normas, a sua coexistência se torna possível.

Em compensação, a certeza objetiva de um sistema de normas tem uma função jurídica real sòmente quando serve ao acôrdo dos reais interêsses do ambiente a que pertence o sistema. A norma implica no conteúdo concreto dos interêsses. $O$ conteúdo concreto dos interêsses implica na objetividade formal da norma. Esta implicação mútua, bem como polaridade de forma e de conteúdo, constitui a peculiaridade do dado jurídico. $\mathrm{O}$ conhecimento do jurista, como representação do dado jurídico, deve, por isso, exprimir sucessivamente aquela implicação e polaridade.

O raciocínio jurídico não é unidimensional, é bidimensional. Sua lei interna é a polaridade. Assim, o problema da interpretação jurídica é o problema de um processo cognoscitivo que implica em si a coexistência de duas atitudes, uma irredutível à outra: uma atitude de adequação ao esquema formal da norma e uma atitude de adequação à evolução do ambiente social em que a norma deve aplicar-se.

3. Pode afirmar-se que o ponto de vista de Reale é institucionalístico. A essência do fenômeno jurídico é a de um ordenamento (ou instituição) que se exprime em normas. Ao puro normativismo contrapõe o aspecto institucional do fenômeno jurídico. Mas, de outro lado, contra o puro sociologismo de alguns autores neo-positivistas que tendem a reduzir o fenômeno jurídico a fato : social, e a conceber o conhecimento jurídico concreto como conhecimento sociológico, faz valer o elemento de objetividade normativa no qual o direito, embora concebido 
como ordenamento, deve necessàriamente exprimir-se (6).

Eis porque, como se viu, êle insiste sôbre a irredutilidade dos dois aspectos do fenômeno jurídico: 1) o fato social como conteúdo, 2) o sistema normativo como forma em que o fato social se objetiva.

De outro lado, mesmo assim concebido, como unidade de forma e de conteúdo, o fenômeno jurídico não revela ainda a sua completa característica. A forma normativa e o conteúdo, - ou seja, a matéria social do direito não esgotam em si mesmos tôda a essência do direito.

O fenômeno jurídico é instituição (e ordenamento), mas ao mesmo tempo tem em si algo que supera o seu próprio caráter de ordenamento normativo. Há em Reale uma exigência puramente filosófica que, se por um lado o impele a assumir uma concepção integral do fenômeno jurídico como ordenamento normativo, por outro lado o propele a ultrapassar a própria concepção institucionalística por êle assumida.

É a exigência de pesquisar nas manifestações exteriores e fenomênicas do direito a essência da realidade jurídica, algo que seja inexaurível às suas próprias manifestações fenomênicas e exteriores. Nesta pesquisa da essência, Reale revela uma atitude crítico-filosófica que o leva a uma espécie de transcendentalismo axiológico. O mérito e o trabalho crítico do autor consiste, sobretudo, no cuidado que demonstra de não cair quer no dogmatismo positivista, quer no dogmatismo racionálísta do direito natural. Por um lado, êle não se limita a uma pura descrição empírica das instituições jurídicas em seus aspectos exteriores, e, por outro, não pode prescindir de tais aspectos institucionalísticos e extrínsecos, nem pode se de-

(6) “A rigor, nem seria necessário falar-se em "norma e situação normada", pois a norma é, ao mesmo tempo, o condicionante e o condicionado, o valor e o fato em uma sintese dinâmica" (De dignitate, loc. cit.). 
dicar à procura de uma pura essência abstrata e ideal do direito concebível além dos ordenamentos jurídicos positivos, em uma esfera separada pressuposta como puramente racional.

A essência do fenômeno jurídico positivo deve ser procurada no fenômeno jurídico positivo mesmo, como sua interna condição de possibilidade, e, por conseguinte, como elemento transcendental condicionante. Esta essência é axiológica. Isto é, a essência interiormente condicionante de um certo fenômeno jurídico positivo é o valor (7). A regra jurídica exprime sempre, com efeito, um juízo de valor.

4. O valor é o elemento que, contra uma pura visão neo-positivista do fenômeno juridico, impede a redução da essếncia da regra jurídica a uma pura e simples relaç̃o de pressupostos e consequências, isto é, a um puro juizo causal ou ainda a um puro juĺzo probabilístico a posteriori, ou, de qualquer modo, a um simples jứzo sintético a posteriori.

A redução das regras jurídicas a puros jứzos de fato, sintéticos a posteriori, levaria a uma equivalência lógica entre leis jurídicas e leis físicas, o que é insustentável. Há um fato fundamental que a impede: um fato verificável através da observação empírica e da experiência externa a que hoje apelam até os neopositivistas, e pelo qual, enquanto os fenômenos da natureza coincidem exatamente com as leis desta, as ações humanas, ao contrá-

(7) “ . de sorte que o Direito passe a ser visto, não mais à luz de uma condicionalidade lógico-transcendental, nos moldes: kantianos, ou de uma condicionalidade empírico-sociológica, segundo a lição de Jhering, mas sim em razão de uma condicionalidade histórico-cultural, ıcapaz de abranger de maneira unitária e dinâmica, os elementos de sua tríplice natureza: lógica, ética e valorativa" (Axiologia, p. II). 
rio, não coincidem sempre com as leis da conduta humana. A coincidência das ações humanas com as leis da conduta é posta por estas, não como um fato que sempre se verifica, mas sim como um dever ser. Uma tal coincidência é posta como um dever-ser, e, portanto, como um valor e não como simples fato, visto como na esfera dos fatos nem sempre se verifica.

Ora, qual é a essência valorativa e axiológica das regras jurídicas em relação às outras regras da conduta? Tal essência é a justiça. A justiça é, segundo Reale, um valor que se distingue dos outros porque é condição de realização de todos os outros valores (8). Ubi homo, ibi societas: Não pode o homem viver a não ser em sociedade e a justiça é um valor cujo conteúdo é constituído por aquele conjunto de condições que, embora variando com o variar dos diversos ambientes e das diversas situações sociais, tornam possível a ordem social.

Reale fala do bem comum como conteúdo da justiça (9). No fundo, o conceito de bem e de interêsse comum pressupõe o conceito de integração dos interêsses individuais emergentes de um determinado ambiente social. $O$ bem comum correspondente a um determinado ambiente social pressupõe a possibilidade de relação e de integração dos interêsses particulares dos indivíduos que nele vivem. $O$ bem comum surge do acôrdo dos interêsses individuais. $O$ interêsse de um indivíduo está em contraste com o bem comum quando está em contraste com o acôrdo dos interêsses alheios.

Dizer que a justiça é um valor que se põe como condição para a realização de outros valores não significa

(8) “ a Justiça é, dentre todos os valores, o único que não tende a afirmar-se em razão de seu conteúdo particular: seu significado está em ser condição e modo para que haja coexistência ide constelações valorativas; o seu valer é um valor para que os valores valham no âmbito da história" (De dignitate, $p$. $54)$.

(9) Fundamentos do direito, cit., p. 311 e segs. 
simplesmente dizer que a justiça é um fim. A justiça pertence à realidade dos valores e a realidade dos valores não é redutivel à realidade dos fins.

Reale, desenvolvendo de maneira original alguns argumentos de Scheler e de Hartmann, defende enèrgicamente a autonomia da esfera axiológica dos valores relativamente à esfera teleológica dos fins, mas, de outro, lado, não concebe uma axiologia que não implique numa Teleologia.

Tôda Teleologia pressupõe uma Axiologia. Os fins são elementos psicológicos; os valores não. A realidade dos valores é a condição transcendental que torna possível a constituição e a escolha psicológica dos fins.

A meu ver, esta posição de Reale poderia ser definida como historicismo axiológico. Êle polemiza ora contra o historicismo puro de caráter idealista, ora contra tôda concepção dos valores como elementos meta-históricos ou de qualquer modo destacados do processo histórico.

Os valores são dados que constituem as diretivas do processo histórico. $\mathrm{O}$ processo histórico é processo espiritual: é o próprio processo em que se desdobra a consciência humana. A história não é uma série de fatos físicos, porque é justamente explicação da consciência. A consciência, isto é, a realidade espiritual, distingue-se da realidade física exatamente em quanto geratriz de valores. A consciência é projeção de valores. A relação entre a consciência de um indivíduo e a de outro, entre a consciência de um indivíduo e o conjunto das consciências dos demais, constitue relações de valores, visto como as consequências se explicam em sua realidade espiritual como projeções de valores.

Reale não desenvolveu ainda uma teoria da alteridade das consciências, nem explicou ainda expressa e definitivamente de que modo a unidade espiritual do processo histórico se forma através da pluralidade das consciências humanas, o que equivale, a dizer, como a pluralidade 
das consciências se desenvolve sem se diluir na unidade do processo histórico, e como, em compensação, se possa falar de história, isto è, de unidade do processo histórico, quando êste processo é constituido pela pluralidade das consciências.

Como se explica e como é configurável, neste caso, a relação de unidade e multiplicidade, sem adotar - dado que Reale não pode adoptar — a explicação apresentada pelas filosofias neo-hegelianas?

l’ois bem, se o nosso autor não desenvolveu ainda uma expressa leoria da pluralidade das consciências, penso contudo que o principio dessa teoria seja por êle sub-entendido. A relação das consciências è, segundo êle, relação axiológica, isto é, relação de valores e de perspectivas de valores. A história, como realidade espiritual viva c humana, e relação de valores.

Reale fala da pessoa humana como valor absoluto que estí implicado em cada forma de experiência moral e juridica (10). E, definitivamente, concebe a pessoa como possibilidade de escolha constitutiva de valores. A pessôa é o fundamento da liberdade. A liberdade não é aqui entendida como pura liberdade empírica, nem como pura ra-cionalidade meta-empírica, mas em sentido axiológico como concreta escolha de valores.

A pessoa é valor absoluto porque condição de afirmação e de atuação de todo sistema de valores. Ofender e destruir a personalidade humana significa ofender e destruir o valor absoluto, isto é, a possibilidade de escolha dos valores. Colocar-se contra a pessoa significa atirar-se contra a comunicação histórica dos valores, a qual só se torna evidentemente possível através da livre eleição dos valores (11).

(10) Liberdade antiga e liberdade moderna, cit., estr., p. 29. Como já o autor se exprimiu em suas lições, "o ser do homem é o seu dever ser".

(12) Ibidem. 
Creio que no pensamento do autor devem estar sublinhados tanto o caráter da pessoa como valor absoluto no sentido ora apontado, quanto o caráter de objetiva relatividade de todos os outros valores. A pessoa é o valor absoluto e incondicionado porque é condição imprescindível da escolha e da communicação de todos os outros valores. Mas, todos os demais são relativos aos ambientes culturais que, nas várias situações históricas, exprimem. A objetividade de um valor, ou de um sistema de valores, coincide com a objetividade do ambiente social e cultural que nele se manifesta. dade relativa, não absoluta, não incondicionada, mas social e històricamente condicionada. Valores que, por' exemplo, num ambiente histórico-social de há mil anos, foram fundamentais podem não mais sê-lo num ambiente histórico-social contemporâneo.

5. Os valores são extruturas históricas. Segundo o pensamento de Reale, não se pode imaginar uma criação de valores que não seja condicionada pela situação histórica em que ocorre (12). Uma experiência de valores determina situações históricas, mas é ao mesmn tempo condicionada por situações históricas precedentes. $O$ passado histórico, as extruturas históricas passadas são condições positivas na experiência dos valores.

O passado histórico não se resolve dialèticamente na presente criação dos valores. Sob êste aspecto é significativa a crítica de Reale à posição neo-hegeliana. 0 passado não é para êle um momento dialético negativo ao presente mas é "momento do espírito condicionante de outras possíveis aberturas e perspectivas da existência humana" (13).

Assim, a axiologia de Reale contrapõe-se àquela concepção axiológica meta-histórica que inclusive no Brasil

(12) Axiologid, p. 9.

(13) Ibidem. 
encontra atualmente um jovem e sagaz representante em Vicente Ferreira da Silva (14). No último escrito de Reale, com efeito, parece-me poder ver alguns traços, embora ainda implícitos e subentendidos de um diálogo com Ferreira que certamente seria filosòficamente proveitoso.

Este último autor, cujo pensamento há pouco analisei e que é um profundo exegeta do existencialismo heideggeriano, chega, com efeito, a uma concepção dos valores como històricamente incondicionados. No fundo, Ferreira concebe a essência do valor como um mito capaz de alterar o curso da história, como fôrça mitológica que transcende tôdas as possibilidades históricas do homem tais como têm sido sistematizadas e configuradas no curso da chamada civilização ocidental.

Êle vê hoje os sintomas de uma crise da civilização e da cultura que teria suas raízes numa crise metafísica da Mistória, como esta tem sido até agora concebida em sentido antropológico e antropocêntrico. Êle vê na história a determinação de um conceito antropocêntrico $c$ indica os sintomas e a possibilidade de uma próxima alteração radical de tal conceito através do surgir de novas forças mitológicas e portanto - de seu ponto de vista - de novos valores.

Dêste modo, Ferreira põe o problema de ruptura radical entre história e valores. Sua atitude é metafìsicamente revolucionária: não revolucionária no sentido político do marxismo, porque, ao contrário, segundo êle, -o marxismo se ajusta perfeitamente no quadro do historicismo e do antropologismo de colocação metafísica tradicional (15).

(14) Para a bibliografia e uma exposição critica do pensamento de Vicente Ferreira da Silva, remeto ao mew ensaio: Motivi fondamentali del pensiero sudamericano, de próxima publicação no "Giornale di Metafisica".

(15) Ibidem. 
Pois bem, quanto a esta e a outras perspectivas de uma axiologia meta-histórica, Reale reafirma o significado historicista de seu ponto de vista. Repele a consideração da possibilidade de um divórcio entre história e valores e, por conseguinte, em suma, de um divórcio radical metafìsicamente relevante, entre valores passados e valores futuros.

"Uma axiologia a-histórica ou meta-histórica, diz não me parece que possa ter sentido, porque é sómente na História e através da História que se aperfeiçoa o conhe cimento do mundo dos valores, embora êstes transcendarı: as contingências do viver historico, o qual jamais logrará captá-los, definitivamente, em todas as suas possibilidades e projeções". (16)

Através da história os valores são racionalizados como fins. O conceito de fim é, num certo sentido, correspondente à racionalização do valor. Racionalizar significa necessàriamente mediar. Por isso a racionalização do valor como fim indica que ele deva ser considerado em relação aos meios idôneos à sua realização. Reale não pode desconhecer, e de fato não desconhece, o nexo entre a realidade do valor e a realidade dos meios idôneos à sua realização. Todavia, êle combate a acentuação que eu fiz (17) do elemento meio em confronto com o elemento valor.

Reale quer combater contra toda possibilidade de resolução do problema moral sôbre o plano naturalista:

(16) Axiologia, p. 9.

(17) Em vários ensáios: Aspefti della critica dei valori ético-giuridici nel pensiero contemporaneo em "Riv. inter. di filosofia del diritto", 1950, estr., p. 34; Valutazioni morali e giuridiche nella crisi dell'ética individuale (Siena, 1950). p. 38 e segs.: Value judgments in ethics and in law (em "Philosophical quarterly", 1951), p. 425 e segs., La crisi della cultura (em "Revista brasileira de filosofia", 1951, p. 386 e segs.) além do trabalho sôbre a moral smithiana citado. 
dos meios. (18) A eleição dos meios, por isto, segundo" êle, não é essencial ao valor, mas é essencial à sua realização histórica como fim. Por outro lado, quer êle jgualmente combater toda consideracão abstrata do valor tal como se verifica quando o valor é considerado exteriormente a seu nexo com as condições de sua realização. Por essa razão afirma a essencialidade de tal nexo, mas, nêsse ambito, sustenta uma polaridade entre valores e meios: uma polaridade na base da qual o valor, embora sendo na sua atuação condicionado aos meios, é todavia suscetível de prevalecer sôbre êles.

Ora, que significado tem esta possibilidade de prevalência dos valores sôbre as condições de sua atuação? Reale dá dois exemplos: a ação heróica e a ação do mártir. Trata-se de ações que se acham no limite extremo da experiência moral, nas quais a conquista dos fins seria despropocionada e prevalecente no que diz respeito à disponibilidade dos meios (19). Em certo ponto, aliás, na sua polêmica contra as formas de naturalismo ético segundo as quais a essência dos valores é vista sòmente em função de sua efetiva possibilidade de realização, Reale declara decisivamente que a ação do mártir é caracterizada "pelo sacrifício extremo por um fim" em uma situação em aue se verifica "uma absoluta carência atua! de meios" (20).

A ação do mártir, em suma, viria a ser caracterizada, segundo o nosso autor, pelo despedaçamento da relação entre meios e fins, pròpriamente por causa de uma "abso-

(18) Sôbre êste aspecto seria interessante confrontar a atitude de Reale com a de um arguto escritor norte-americano: $E$. Vivas, em um livro rico da vivacidade latina - The moral life and the ethical life (Chicago, 1950) - e fortemente polêmico com relação às concepções morais pragmatistas e positivistas.

(19) Axiologia, p. 5.

(20) Ibidem. 
luta falta" de meios e não sòmente por uma supremacia do valor sôbre as condições materiais de sua realização.

Levando-se em conta êste exemplo, podemos então, a meu ver, sintetizar o pensamento de nosso autor nos três pontos seguintes: 1) a experiência moral é sempre caracterizada por um nexo de implicação de valores e meios idôneos à sua realização; 2) no âmbito dêsse liame de imrplicação revela-se sempre a irredutibilidade dos valores à escolha dos fins e dos meios em que se determinam as. ações pelas quais os valores mesmos se realizam; 3) a despeito dos dois pontos de vistas precedenies (1 e 2), na margem extrema da experiência moral há tipos de ações em que o mencionado nexo de valor e de meios acaba irremediàvelmente por se despedaçar, casos em que portanto, o valor se revela por si mesmo, em uma "absoluta falta" de meios.

A mesma razão que me leva a considerar como aceitáveis e convincentes os dois primeiros pontos de vista me deixa suspenso quanto ao terceiro. As razões por que devo confessar que algumas críticas suscitadas pelo professor Reale me deixaram convencido são as razões mesmas pelas quais fico em dúvida diante da configuração de um tipo de ações, à margem da experiência moral, caracterizadas por uma "absoluta falta" de meios.

Para mim, a grande verdade da posição de Reale, a que mais revela a sua sensibilidade crítica, assim como a modernidade no tratamento dos problemas morais, consiste na perspectiva do nexo de axiologia e teleologia; axiologia e historicidade; valores e meios indôneos $\dot{a}$ sua realização. A pesquisa de Reale revela tôda a sua penetração crítica quando nos visualisa os supra-mencionados nexos concretos de implicação.

Seu modo de raciocinar atinge, a meu ver, os seus melhores resultados quando procede por polaridade, quando, através da particularidade de suas indagações, chega a enuclear na variedade das ações e das situações a interna polaridade da experiência moral e jurídica. 
A dialética da realidade concreta não é configurável através de uma síntese de elementos opostos dos quais um se resolva no outro, dos quais um seja o superamento do outro, como na dialética de tipo hegeliano e também - a despeito da diferença - na dialética marxista.

A dialética do concreto, a que exprime verdadeiramente a extrutura do processo histórico, é a dialética $d a$ polaridade: não é uma dialética resolutiva, visto que não implica, em si mesma, na posição de uma sintese resolutiva como condição imanente do seu processo.

$\mathrm{Na}$ raiz de semelhante dialética existe, segundo penso, o fundamento paradoxal e insuperàvelmente antinômico da realidade humana em seu irredutivel dualismo constitutivo de realidade emocional e de realidade racional. É o nexo concreto de emocional e de racional concebível como nexo de valores e meios: os valores como resultado de uma projeção do elemento emocional da natureza humana e a relação racional de meios a fins como condição de possibilidade da realização dos valores nas situações históricas particulares.

O nexo concreto dos valores e dos meios é assim uma dualidade irredutível, cujos elementos não podem ser reduzidos a um, sem que sejam abstratamente deformados. Os vários aspectos da vida prática para que sejam vistos em concreto devem ser vistos em função daquela insuperável dualidade. Mas Reale talvez não tenha resistido à tentação de resolver os dois elementos em um, quando, como se viu, no limite da experiência moral nos apresentou a ação do mártir como a conquista absoluta de um valor posto além e fora de tôda relação de meios e fins. Será, porem, a ação do mártir mesmo caracterizada por uma absoluta falta de meios? O sacríficio de algo de fundamental — quer seja a vida, ou outra coisa - não é o imprescindível meio de realização que distingue nitidamente a ação do mártir? 